\author{
SANDIA REPORT \\ SAND2010-2140 \\ Unlimited Release \\ Printed April 2010
}

\title{
Parameter Study of a Vehicle-scale Hydrogen Storage System
}

Terry A. Johnson and Michael P. Kanouff

Prepared by

Sandia National Laboratories

Albuquerque, New Mexico 87185 and Livermore, California 94550

Sandia National Laboratories is a multi-program laboratory operated by Sandia Corporation, a wholly owned subsidiary of Lockheed Martin company, for the U.S.

Department of Energy's National Nuclear Security Administration under contract DE-AC04-94AL85000.

Approved for public release; further dissemination unlimited. 
Issued by Sandia National Laboratories, operated for the United States Department of Energy by Sandia Corporation.

NOTICE: This report was prepared as an account of work sponsored by an agency of the United States Government. Neither the United States Government, nor any agency thereof, nor any of their employees, nor any of their contractors, subcontractors, or their employees, make any warranty, express or implied, or assume any legal liability or responsibility for the accuracy, completeness, or usefulness of any information, apparatus, product, or process disclosed, or represent that its use would not infringe privately owned rights. Reference herein to any specific commercial product, process, or service by trade name, trademark, manufacturer, or otherwise, does not necessarily constitute or imply its endorsement, recommendation, or favoring by the United States Government, any agency thereof, or any of their contractors or subcontractors. The views and opinions expressed herein do not necessarily state or reflect those of the United States Government, any agency thereof, or any of their contractors.

Printed in the United States of America. This report has been reproduced directly from the best available copy.

Available to DOE and DOE contractors from

U.S. Department of Energy

Office of Scientific and Technical Information

P.O. Box 62

Oak Ridge, TN 37831

Telephone: $\quad$ (865) 576-8401

Facsimile: $\quad$ (865) 576-5728

E-Mail: $\quad$ reports@adonis.osti.gov

Online ordering: http://www.osti.gov/bridge

Available to the public from

U.S. Department of Commerce

National Technical Information Service

5285 Port Royal Rd.

Springfield, VA 22161

Telephone: (800) 553-6847

Facsimile: $\quad$ (703) 605-6900

E-Mail: $\quad$ orders@ntis.fedworld.gov

Online order: $\quad$ http://www.ntis.gov/help/ordermethods.asp?loc=7-4-0\#online

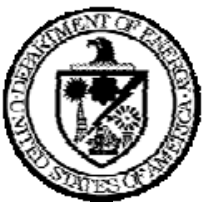


SAND2010-2140

Unlimited Release

Printed April 2010

\title{
Parameter Study of a Vehicle-scale Hydrogen Storage System
}

\author{
Terry Johnson and Michael P. Kanouff \\ Thermal/Fluids Science and Engineering 8365 \\ Sandia National Laboratories \\ P.O. Box 969 \\ Livermore, CA 94551
}

\begin{abstract}
Sandia National Laboratories has developed a vehicle-scale prototype hydrogen storage system as part of a Work For Others project funded by General Motors. This Demonstration System was developed using the complex metal hydride sodium alanate. For the current work, we have continued our evaluation of the GM Demonstration System to provide learning to DOE's hydrogen storage programs, specifically the new Hydrogen Storage Engineering Center of Excellence.

Baseline refueling data during testing for GM was taken over a narrow range of optimized parameter values. Further testing was conducted over a broader range. Parameters considered included hydrogen pressure and coolant flow rate. This data confirmed the choice of design pressure of the Demonstration System, but indicated that the system was over-designed for cooling.
\end{abstract}

Baseline hydrogen delivery data was insufficient to map out delivery rate as a function of temperature and capacity for the full-scale system. A more rigorous matrix of tests was performed to better define delivery capabilities.

These studies were compared with 1-D and 2-D coupled multi-physics modeling results. The relative merits of these models are discussed along with opportunities for improved efficiency or reduced mass and volume. 


\section{ACKNOWLEDGMENTS}

The authors would like to acknowledge the contributions of a number of individuals that contributed to this work. The design of the Demonstration System was completed by a team including engineering by Daniel Dedrick, mechanical design by Yon Perras and Sal Birtola, and computational analysis by Brian Rush, Greg Laskowski, Greg Evans, and Aili Ting. The test facility was designed and assembled by Daniel Dedrick, Yon Perras, George Sartor, Mark Zimmerman, Dan Knight, Dave Zanini, Tom Raber, Matthew Klein, and Ryan Andrade. 


\section{CONTENTS}

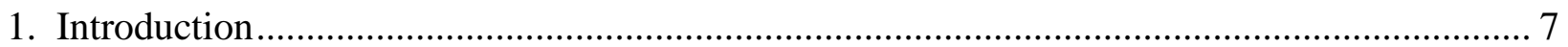

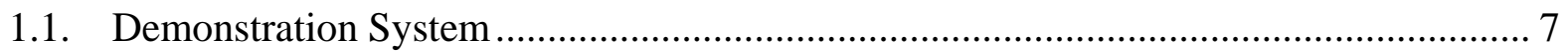

1.2. Computational models ........................................................................................ 9

1.2.1. Chemical kinetics.................................................................................... 9

1.2.2. Thermal conductivity .................................................................................... 10

1.2.3. Hydrogen Permeability ……………………................................................ 11

1.2.4. 1-D Multiphysics Tube Model .......................................................................... 12

1.2.5. 2-D Multiphysics Tube Model ………………….............................................. 13

1.2.6. 2-D Heat Exchanger Model............................................................................... 13

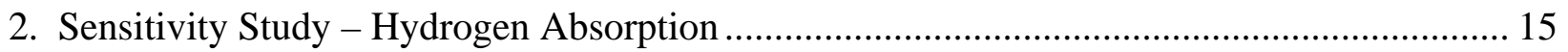

2.1. Effect of Hydrogen Pressure ................................................................................... 15

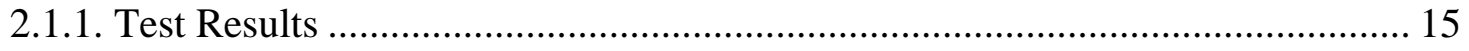

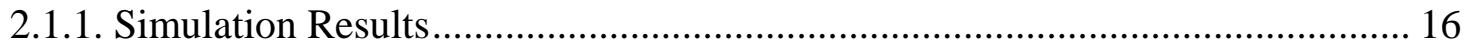

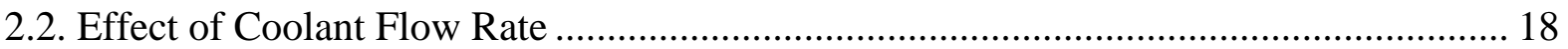

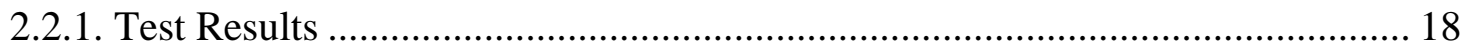

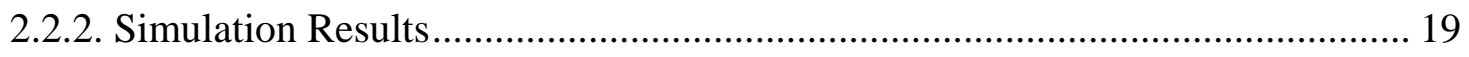

3. Sensitivity Study - Hydrogen Desorption …………………………………………………... 21

3.1. Effect of Temperature and Capacity - Tet Phase ……………………………................. 21

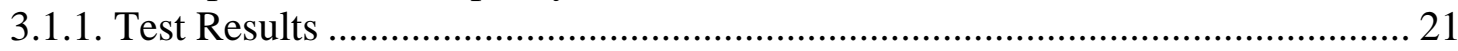

3.1.2. Simulation Results.......................................................................................... 23

3.2. Effect of Temperature and Capacity - Hex Phase ................................................................ 24

3.2.1. Test Results ............................................................................................... 24

3.2.2. Simulation Results............................................................................................ 25

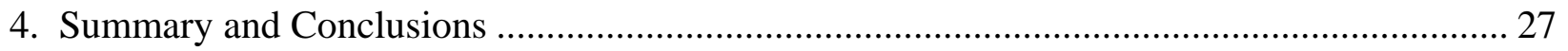

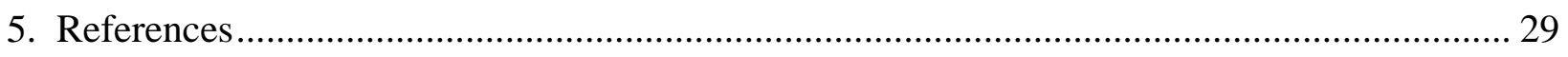

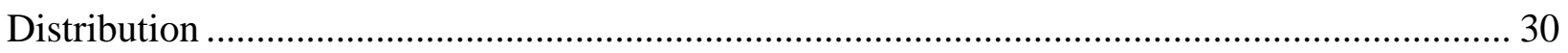

\section{FIGURES}

Figure 1. Demonstration System hydrogen storage module......................................................... 8

Figure 2. Module tube.................................................................................................... 9

Figure 3. Comparison of chemical kinetics model predictions with experimental data ................ 10

Figure 4. Effective thermal conductivity of sodium alanate/ENG mixtures ............................... 11

Figure 5. 2-D axisymmetric model of a module tube with coupled multi-physics........................ 13

Figure 6. 2-D conjugate heat transfer model of a module heat exchanger .................................... 14

Figure 7. Experimental results showing the effect of hydrogen pressure on refueling rate. ........ 16 Figure 8. Simulation predictions of the effect of hydrogen pressure on refueling rate. 1-D model (left), 2-D model (center), and enhanced 1-D model (right).............................................. 17

Figure 9. Effect of coolant flow rate on refueling rate ............................................................... 19

Figure 10. 2-D model predictions of the effect of coolant flow rate on refueling rate ................. 20 
Figure 11. Effect of temperature and capacity on hydrogen delivery rate of the tetrahydride phase of a single module...

Figure 12. Simulation predictions of the effect of temperature and capacity on hydrogen delivery rate of the tetrahydride phase of a single module. 1-D model (left), 2-D model (center), and enhanced 1-D model (right).

Figure 13. Effect of temperature and capacity on hydrogen delivery rate of the hexahydride phase of a single module...

Figure 14. Simulation predictions of the effect of temperature and capacity on hydrogen delivery rate of the hexahydride phase of a single module. 1-D model (left), 2-D model (center), and enhanced 1-D model (right). 


\section{INTRODUCTION}

As a key step towards a fully developed hydrogen-based transportation system, the United States Department of Energy (USDOE) along with most automobile manufacturers is focused on developing passenger vehicles powered by hydrogen fuel cells. Major manufacturers around the world are now targeting commercial sales of fuel cell vehicles in middle of the decade, notably Daimler in Europe, Toyota in Asia, and General Motors in North America. Current demonstration vehicles are fueled by either compressed gas or liquid hydrogen. These physical containment storage tanks will be sufficient for the initial launch of hydrogen fueled vehicles, but are insufficient to satisfy the USDOE and auto industry requirements for more compact, lighter, and less expensive methods [1]. Thus, hydrogen storage is recognized as one of the main technological barriers to the commercialization of fuel cell vehicles.

As part of General Motors' fuel cell vehicle program, they have developed a broad portfolio of hydrogen storage research and development. Along with chemical hydrides and sorption materials, GM's program includes complex metal hydrides. Complex hydrides targeted for automotive applications offer the benefit of high hydrogen capacity but are typically characterized by relatively high reaction enthalpy, low thermal conductivity, elevated hydrogen release temperatures, and slow kinetics at lower temperatures. Several corporations and governments have funded significant materials research to develop improved complex hydrides.

To complement GM’s materials research efforts, they have engaged Sandia National Laboratories to develop an advanced hydrogen storage system based on the complex hydride sodium alanate. Catalyzed sodium alanates are complex hydrides that release and absorb hydrogen in a two step decomposition and recombination reaction shown below (without catalyst):

$$
\begin{array}{ll}
\mathrm{NaAlH}_{4} \Leftrightarrow 1 / 3 \mathrm{Na}_{3} \mathrm{AlH}_{6}+2 / 3 \mathrm{Al}+\mathrm{H}_{2} & \text { Equation } 1 \\
\begin{array}{l}
\text { and, } \\
1 / 3 \mathrm{Na}_{3} \mathrm{AlH}_{6}+2 / 3 \mathrm{Al}+\mathrm{H}_{2} \Leftrightarrow \mathrm{NaH}+\mathrm{Al}+3 / 2 \mathrm{H}_{2}
\end{array} & \text { Equation 2 }
\end{array}
$$

Typically considered as a single hydrogen storage material, sodium alanate is probably the most well characterized complex hydride in the literature today. Also, despite significant global efforts to discover a better material, sodium alanate remains the prototypical complex hydride for automotive applications because of its reversibility at moderate temperature and pressure. As such, this material was chosen as the storage medium for the GM/Sandia hydrogen storage engineering project. This project was a 5 year effort to develop an optimized system design utilizing advanced concepts for hydrogen storage with complex hydrides. The culmination of this project is a $3 \mathrm{~kg}$ stored hydrogen demonstration system that has been designed, fabricated, and tested at Sandia [2].

\subsection{Demonstration System}

The hydrogen storage system developed by Sandia, hereafter referred to as the Demonstration System, consists of four identical storage modules. Each module consists of twelve stainless 
steel tubes that contain the sodium alanate. The tubes are arranged in a staggered, $4 \times 3$ array and enclosed by a steel shell to form a shell and tube heat exchanger. Figure 1 shows the module design. Temperature control during hydrogen absorption and desorption is accomplished by circulating a heat transfer fluid through each module shell. The fluid enters one end of the module through a manifold and flows through six baffled sections before exiting at the opposite end. The baffles force the fluid into a cross-flow path to maximize heat transfer. Hydrogen enters and exits the modules through a 1/4" manifold attached to one end of the tubes. Each module has a nominal hydrogen capacity of 750 grams.

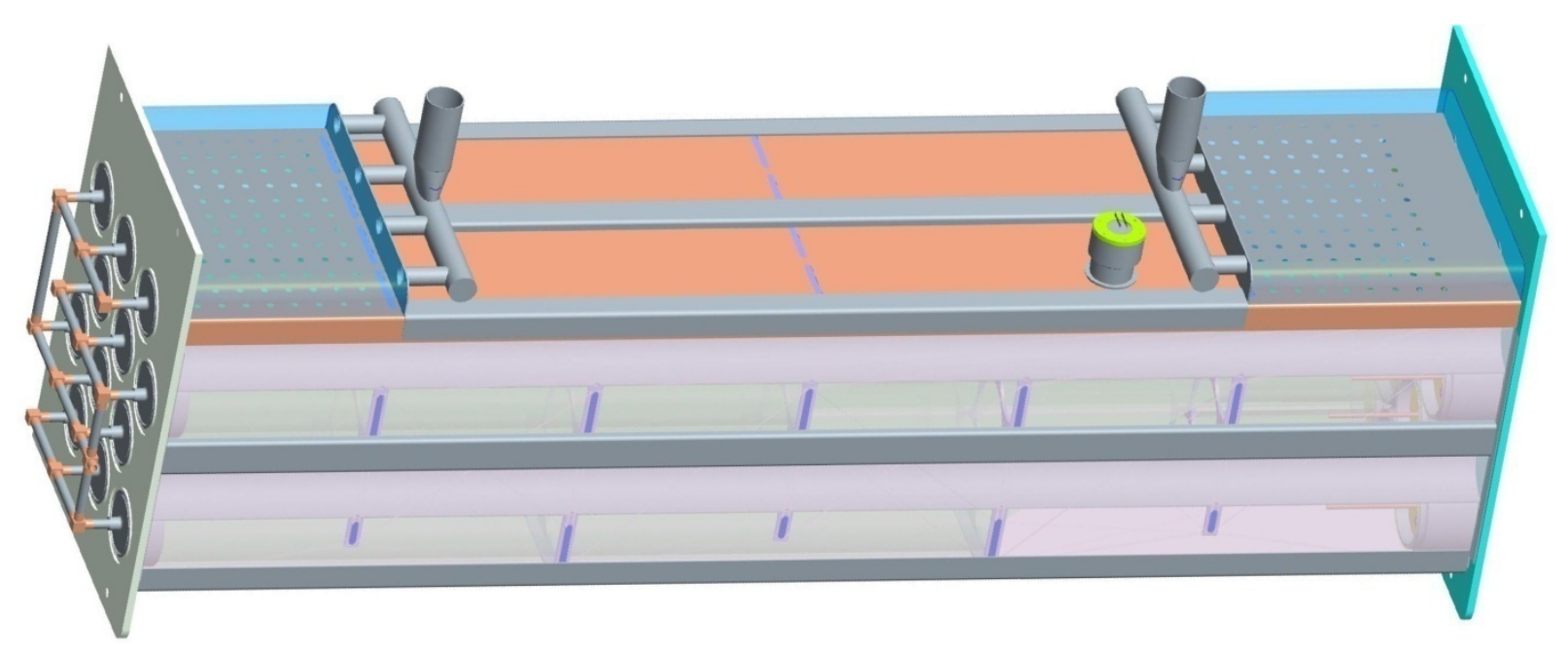

Figure 1. Demonstration System hydrogen storage module.

As shown in Figure 2, each tube has an internal diameter of 2.01" and is about 34” long. The tubes are made from 0.120 " thick 316L stainless steel and are rated for a working pressure of 2000 psi hydrogen. Each tube contains a 9:1 modified sodium alanate/ graphite mixture catalyzed with titanium and packed to a density of $1.0 \mathrm{~g} / \mathrm{cc}$, resulting in a mass of $1.92 \mathrm{~kg}$ of material per tube and $23.0 \mathrm{~kg}$ per module. The graphite is added to improve heat transfer by increasing the effective thermal conductivity of the mixture. Figure 2 shows a close up view of both ends of a tube. The hydrogen port is shown on the left. The end shown on the right was used to load the tube with sodium alanate and is sealed with a threaded plug. The plug, shown in the upper image, includes a thermocouple well for measuring the internal temperature of the material during operation. 


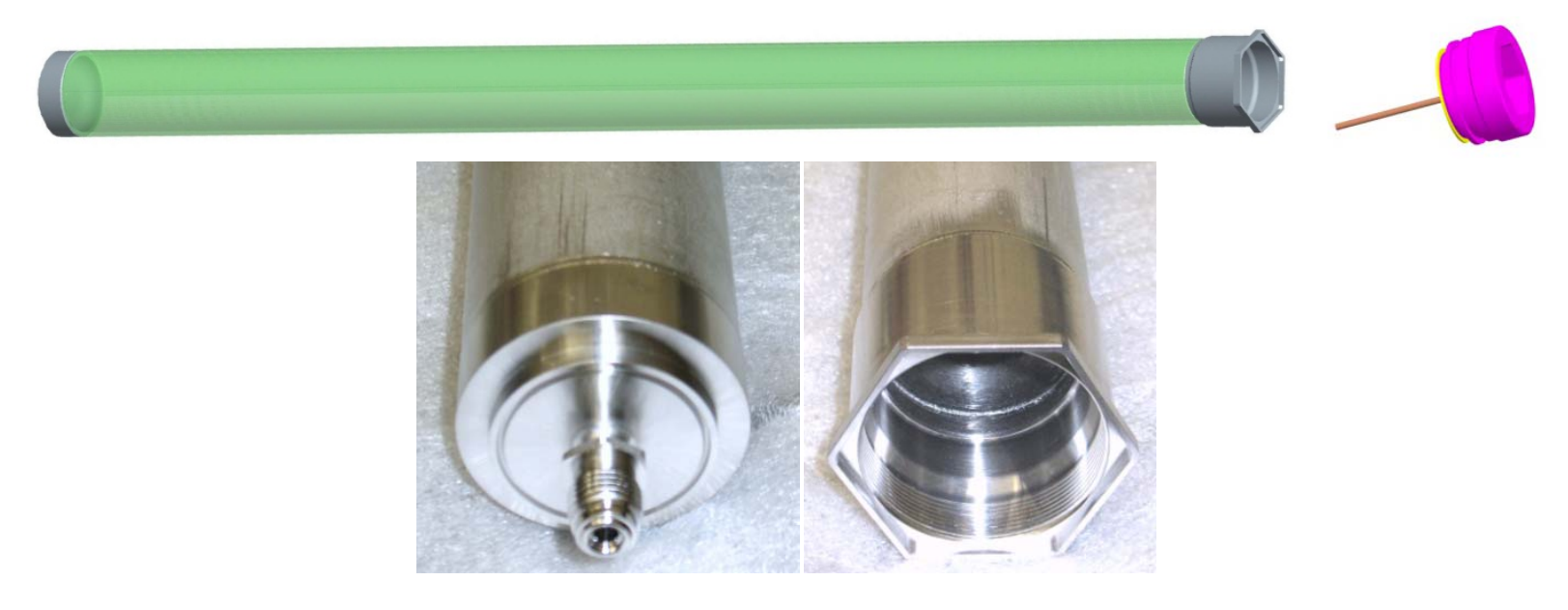

Figure 2. Module tube.

\subsection{Computational models}

To develop an optimized design for a hydrogen storage system based on a complex metal hydride like sodium alanate requires an understanding of the fundamental processes involved in the hydriding/dehydriding reaction. This understanding includes thermodynamics, chemical kinetics, heat transfer, and mass transfer within the porous solid, which are all closely coupled. To understand and make use of this coupled set of physics, computational models were developed [1]. The design process for the Demonstration System made use of a number of computational models ranging from models to describe material properties to multi-component system level simulations.

\subsubsection{Chemical kinetics}

At the core of the higher level computational simulations used for the Demonstration System design was a chemical kinetics model of the hydriding and dehydriding reactions of sodium alanate shown in Equations 1 and 2 above. A more detailed description of this model can be found in Reference 1 . The general form of the model is given by the equation,

$$
R=k^{*} e^{(Q / R T) *\left(P^{n}-P_{e q}{ }^{n}\right) * S}
$$

Equation 3

where $\mathrm{R}$ is the reaction rate, $\mathrm{k}$ is the pre-exponential rate constant, $\mathrm{Q}$ is an activation energy, $\mathrm{P}$ is the hydrogen pressure, $\mathrm{P}_{\mathrm{eq}}$ is the temperature-dependant equilibrium pressure for the reaction, and $\mathrm{S}$ is a solid interaction term that is a function of species concentrations. The constants $\mathrm{k}, \mathrm{Q}$, and $\mathrm{n}$ must be found by fitting model predictions to experimental results. For the Demonstration System design, model constants were fit to a set of experiments designed specifically for that purpose. Figure 3 shows comparisons of model predictions to experimental results for a hydrogen absorption and desorption. 

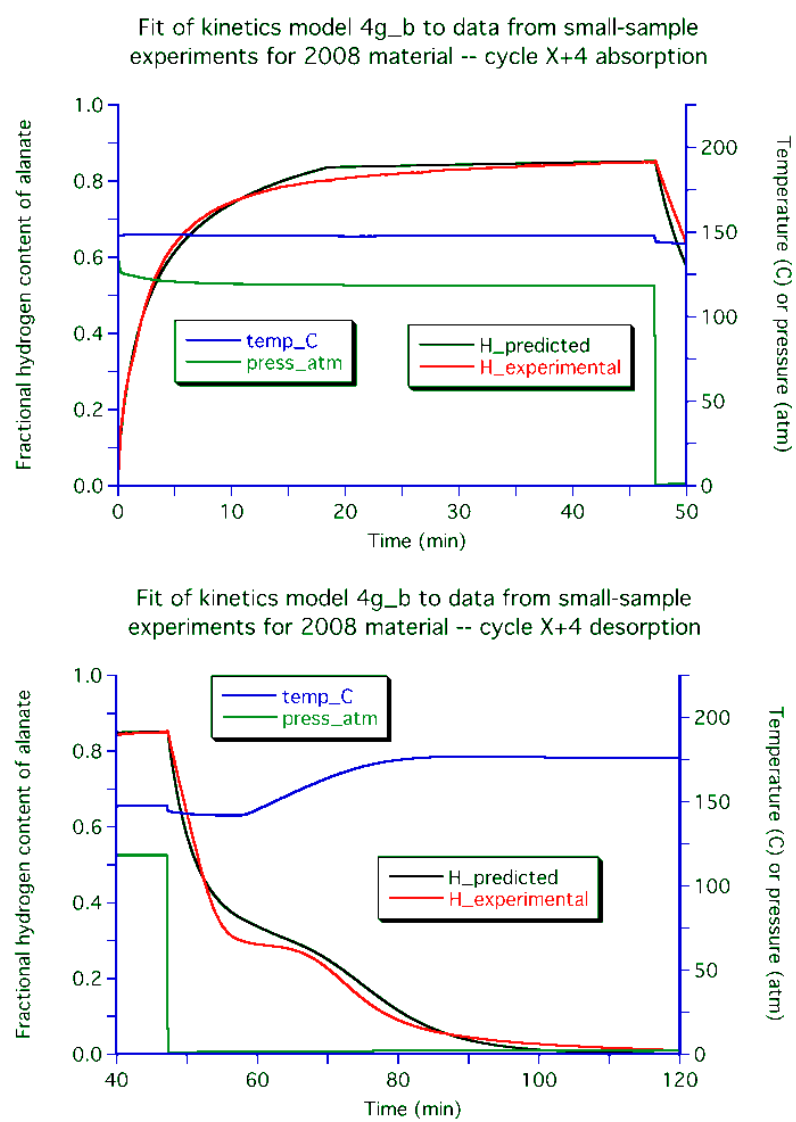

Figure 3. Comparison of chemical kinetics model predictions with experimental data

\subsubsection{Thermal conductivity}

Sodium alanate thermal properties were needed to carry out heat transfer analyses for the Demonstration System design. Heat capacity and thermal conductivity, in particular, were required. While heat capacity was estimated based on the constituents of sodium alanate, thermal conductivity was determined experimentally.

As discussed in [1] and [3], the thermal conductivity of sodium alanate was measured using the Thermal Probe Method based on ASTM D 5334. This method is based on transient heat transfer rather than steady thermal gradients and is most appropriate for low conductivity materials. However, even with additional aluminum, the thermal conductivity of sodium alanate was too low for the Demonstration System design and other methods for enhancing the thermal conductivity of the material were investigated.

A literature search indicated that expanded natural graphite (ENG) fibers might be the highest efficiency additive for enhancing the thermal conductivity of sodium alanate. Experiments had shown that thermal conductivities as high as $10 \mathrm{~W} / \mathrm{mK}$ could be attained with ENG mass fractions as low as 5\% with other materials [4]. So, this method was pursued for the Demonstration System. 
Experiments were carried out to understand the mass fraction of ENG fibers required to produce a specific thermal conductivity when mixed with sodium alanate. To characterize the effective thermal conductivity of sodium alanates mixed with ENG fibers, a new experimental apparatus was developed along with a modeling capability. Figure 4 shows the results of this work. The plot shows the effective thermal conductivity of sodium alanates mixed with ENG fibers at 5\% and $10 \%$ mass loading compared to sodium alanates alone. Note that the sodium alanates depicted here include extra aluminum, thus the relatively high baseline thermal conductivity values. Thermal conductivity is shown as a function of hydrogen capacity so that the measurements span the sodium hydride, hexahydride (hex), and tetrahydride (tet) phases. The data in Figure 4 were curve fit to a polynomial and subsequently used in heat transfer analyses as part of the Demonstration System design. The mathematical expression for this curve fit is represented by the following polynomial in the units of $10^{-2} \mathrm{~W} / \mathrm{cm}-\mathrm{K}$,

$$
k(\psi, E)=11.7 \psi^{4}-32.5 \psi^{3}+33.2 \psi^{2}-14.8 \psi+40 E+3.4
$$

Equation 4

where $\Psi$ is the fractional hydrogen content (0-1, relative to $4.4 \mathrm{wt} \%)$ and $E$ is the weight fraction of ENG.

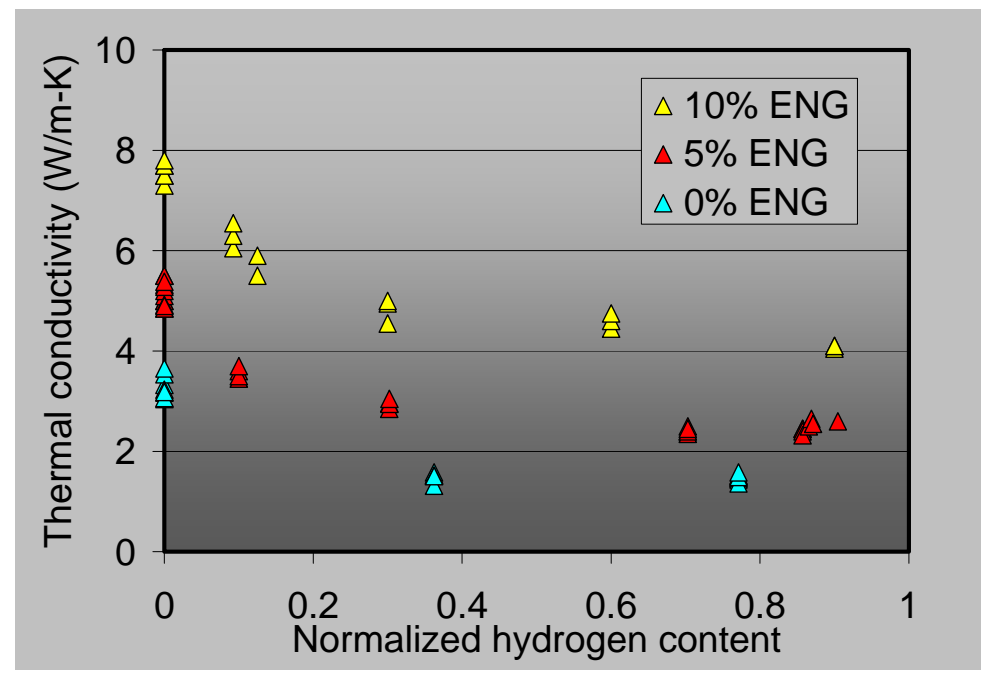

Figure 4. Effective thermal conductivity of sodium alanate/ENG mixtures

\subsubsection{Hydrogen Permeability}

The permeability of the porous medium is defined as

$$
K=\frac{\mu V}{d p / d x}
$$

Equation 5

The 'Ergun' model, which is found to be appropriate for many systems, gives the permeability as a function of the porosity and the diameter of the particles that form the compact. This is an appropriate model for continuum flows; however, in large Knudsen number flows, the model can provide a poor prediction of the relationship between flow rate and pressure drop. High surface 
area solid-phase hydrogen storage beds are frequently characterized by small particle sizes and low void fractions which can lead to the presence of molecular or transition flow regimes, i.e., large Knudsen number flows. Both continuum and rarified flow regimes can be experienced, and models that do not accommodate Knudsen effects result in poor flow field predictions. To accommodate these diverse flow regimes, the Young and Todd model was selected. It gives the permeability as

$$
K=\frac{\phi}{\tau^{2}} d_{p}^{2}\left[\frac{1}{32}+\frac{5}{12} K n\right]
$$

where $d_{p}$ is the pore diameter and $\tau$ is the tortuosity. Porosity is determined through sample mass and volume measurements. There are two limitations to this model. First, in practice, hydride beds have a distribution of pore diameters, $d_{p}$. To address this, the pore diameter is treated as an experimental fit parameter and compared to SEM imaging analysis of the compacted bed. Secondly, the tortuosity, $\tau$, is very difficult to measure and therefore must be inferred from experimental data.

\subsubsection{1-D Multiphysics Tube Model}

The material property models just discussed were used in two primary geometric models of the hydrogen storage system. The first of these was a one-dimensional model of a single hydrogen storage tube. This model included coupled chemical kinetics and heat transfer, but assumed only radial variations in temperature and chemical composition. The model was developed using Matlab and included the detailed sorption kinetics model discussed in section 1.2.1. Given an initial sodium alanate composition profile, the rate equations were integrated using a specified hydrogen pressure and a computed temperature profile. The temperature profile was calculated from an initial condition based on conduction heat transfer within the alanates. The thermal conductivity model shown previously was used for these calculations along with heat flux and/or convective boundary conditions on the outer tube surface and a volumetric heat source term from the chemical reaction rate. Thus, the two sets of equations were coupled. Note that since axial variations were ignored, a constant and uniform hydrogen pressure was assumed and permeability was neglected.

This fairly simple model was used extensively in the design of the Demonstration System. For refueling, the model was used to optimize tube diameter given constraints on refueling pressure and cooling temperature. It was also used to develop optimum refueling pressure profiles for specified tube diameter, cooling temperature and alanate thermal conductivity. Cooling loads for refueling the Demonstration System were also calculated with this model. For hydrogen delivery, the model was used to predict delivery rates for specified temperature and pressure conditions. It was also used to determine the amount of heat that must be provided to the Demonstration System to meet specified hydrogen delivery requirements. This information was used, in turn, to size the heating system for the Demonstration System.

As useful as this simple, 1-D model was, the assumption of axial uniformity limited its accuracy. We knew that the long aspect ratio of the Demonstration System tubes coupled with the finite 
permeability of the alanates would create pressure gradients during hydrogen refueling and delivery. To accurately represent this effect, a 2-D model was needed.

\subsubsection{2-D Multiphysics Tube Model}

For a more detailed representation of the key physics involved in the Demonstration System operation, a two-dimensional axisymmetric model of a hydrogen storage tube was developed. This model was built using Comsol Multiphysics. The model included the complete geometry of a single module tube represented in 2-D as shown in Figure 5. It includes the thermocouple well used in the experiments to access alanate temperatures, as well as the hydrogen inlet stem.

All of the relevant sodium alanate properties were represented in the model. The chemical rate equations were integrated with heat transfer and mass transfer calculations. For heat transfer, both radial and axial temperature gradients were calculated using conduction heat transfer within the alanates with phase-dependant thermal conductivity. A convection boundary condition [i.e., $\mathrm{kdT} / \mathrm{dr}=\mathrm{h}\left(\mathrm{T}_{\mathrm{o}}-\mathrm{T}\right)$ ] for the energy equation was used on the outer surface of the tube to simulate the effect of the oil flow. The heat transfer coefficient $\left(\mathrm{h}=0.065 \mathrm{~W} / \mathrm{cm}^{2} / \mathrm{K}\right)$ was determined from experimental data.

Mass transfer of hydrogen was modeled such that radial and axial pressure gradients were calculated based on boundary conditions and the alanate permeability model. A pressure boundary condition for the momentum equation was applied to the end of the inlet stem to calculate the flow of hydrogen into the tube. A constant or time dependant pressure boundary condition could be used. The permeability model shown in section 1.2.3. was included in the momentum equation to calculate the 2-D pressure profile.

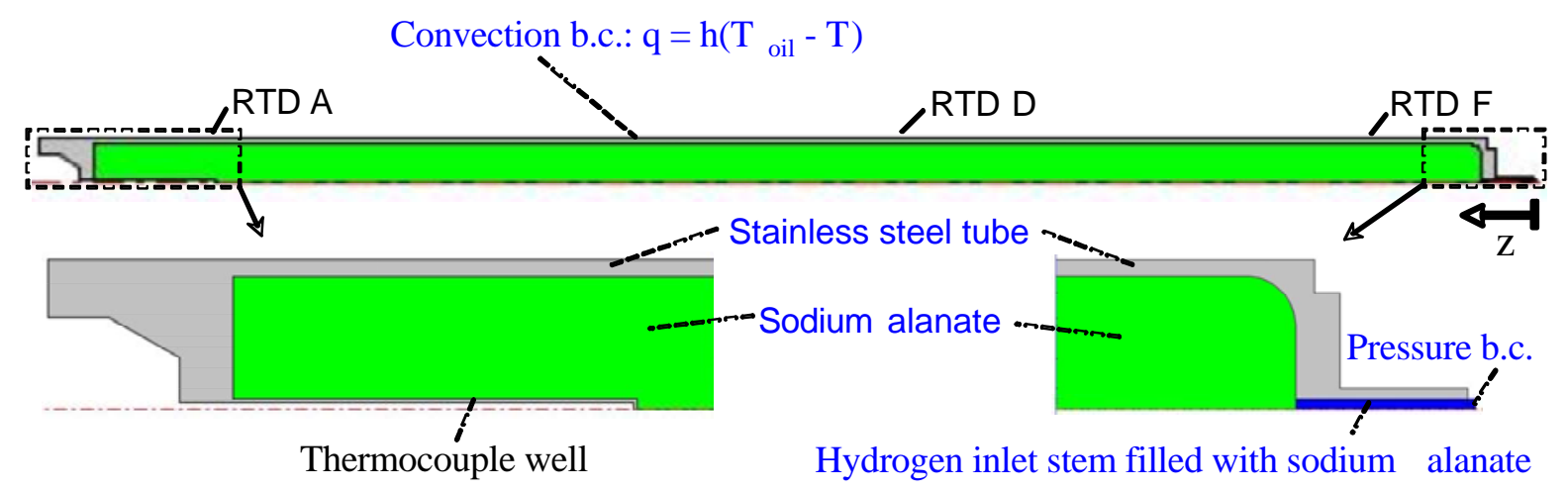

Figure 5. 2-D axisymmetric model of a module tube with coupled multi-physics

\subsubsection{2-D Heat Exchanger Model}

For the Demonstration System design, a coupled fluid dynamics and conjugate heat transfer model was developed to accurately predict local heat transfer rates, temperature variations, and fluid pressure drop within a module. A 2-D model was created to simulate the cross flow of oil over the 12 module tubes. This model represented a midplane slice through a tube pass. The model included a heat flux boundary condition in the inner wall of each tube to simulate the heat 
from the peak absorption rate. Conduction of this heat through the tube wall and convection to the fluid were simulated. Two different domains and mesh densities were used to determine the effect on results. These are shown in Figure 6. Calculations for both laminar and turbulent flow were carried out. This 2-D model provided calculations of both heat transfer coefficient and fluid pressure drop. The heat transfer coefficient was used in the boundary conditions for the tube models discussed above.
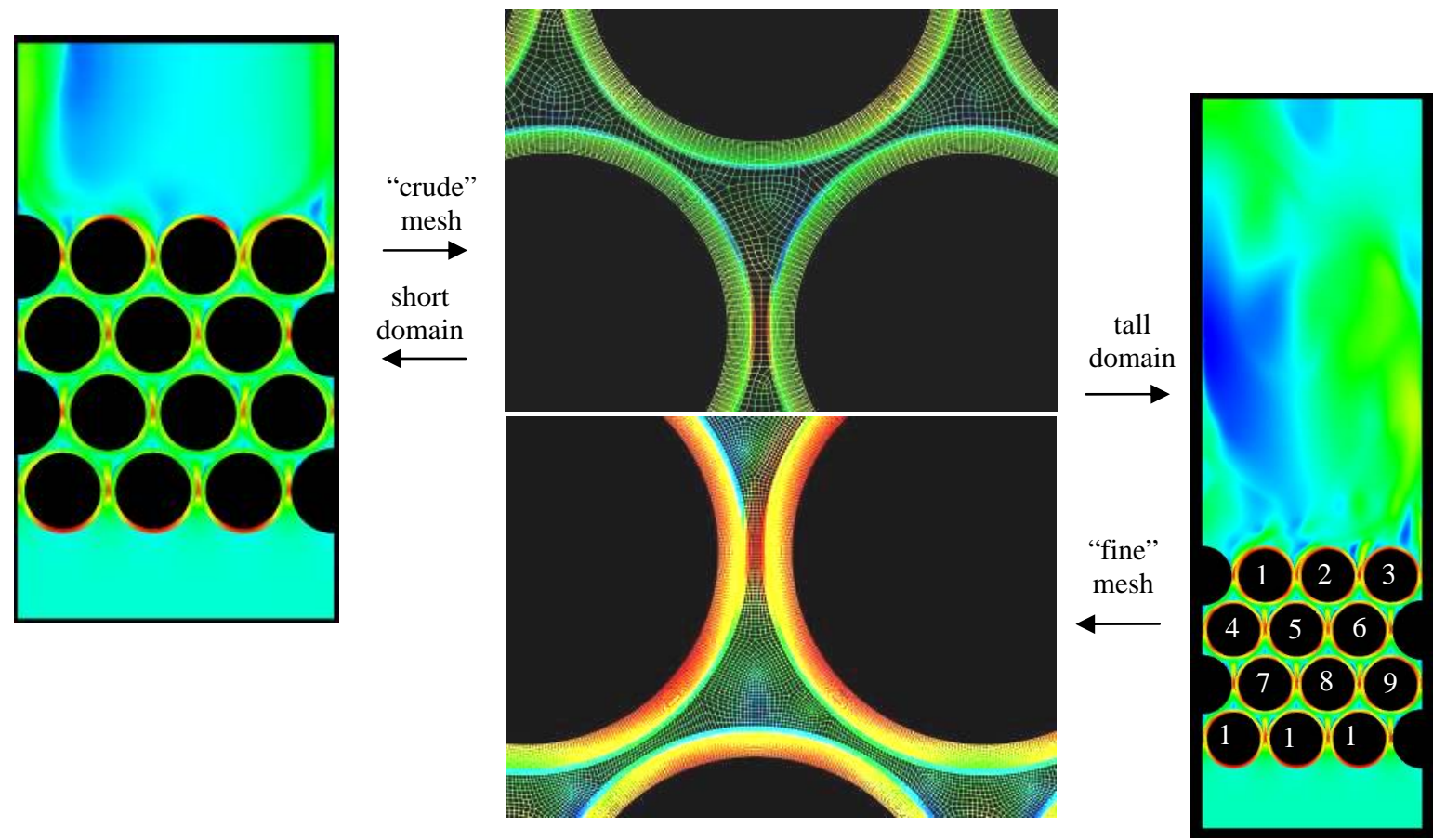

Figure 6. 2-D conjugate heat transfer model of a module heat exchanger 


\section{SENSITIVITY STUDY - HYDROGEN ABSORPTION}

For hydrogen absorption, the Demonstration System was designed to operate at a hydrogen pressure of 2000 psi with oil cooling at a flow rate of $37.5 \mathrm{gpm}$ and an inlet temperature of 140 ${ }^{\circ} \mathrm{C}$. These parameters were chosen based on simulation predictions for optimized performance. Experiments and simulations will be discussed below that consider parameter values other than those for optimized performance. The results will indicate how sensitive the system performance is to each of these parameters. Also, these results will indicate how closely various simulations match with actual data.

\subsection{Effect of Hydrogen Pressure}

\subsubsection{Test Results}

Simulations using the 1-D model were used to find the optimum hydrogen pressure for refueling the Demonstration System. This analysis was based on competing trends. First, absorption kinetics increase with increasing hydrogen pressure. Second, system mass increases with increasing hydrogen pressure since thicker walled vessels are required. At some pressure, the increased system mass will overcome the increase in hydrogen capacity such that the net system hydrogen mass fraction reaches a maximum. The results of this simulation study showed that system mass efficiency peaked near a hydrogen pressure of 2000 psi. Also, the simulation predicted a fairly flat response. In other words, hydrogen pressure did not have a strong effect on system mass efficiency. So, the Demonstration System was designed for a maximum operating pressure of $2000 \mathrm{psi}$.

While 2000 psi was the maximum hydrogen pressure the Demonstration System was designed for, heat transfer limitations prevented the system from being refueled at this pressure continuously. The exothermic hexahydride phase reaction was too rapid at this pressure and produced more heat than could be removed. To solve this issue, an automated hydrogen control scheme was employed. The refueling tests would begin at a lower pressure then, once the hex phase was nearly complete, the hydrogen pressure would be stepped up to $2000 \mathrm{psi}$ for the tet phase absorption. This second phase was the rate limiting step in the refueling process and it was this rate which was optimized. For fast refueling, all of the GM tests finished at 2000 psi.

So, to demonstrate the effect of hydrogen pressure on refueling time, new tests were performed at lower pressure. Figure 7 shows a series of three refueling tests with identical test parameters except for the final hydrogen pressure. These tests were run at an initial pressure of $1100 \mathrm{psi}$ with a coolant temperature of $145^{\circ} \mathrm{C}$ as the bottom two plots indicate. For the hex phase absorption, all three tests were nearly identical in terms of refueling rate and alanate temperature. Once the hex phase was nearly complete, the hydrogen pressure was increased. The blue curves show the result of $2000 \mathrm{psi}$, the green curves show the result of $1800 \mathrm{psi}$, and the red curves show the result of 1600 psi. As expected, there is a significant increase in capacity from 1600 psi to 1800 psi and 1800 psi to 2000 psi. This is due to a combination of thermodynamics and kinetics. The alanate thermodynamics requires the temperature to drop much lower before hydrogen is absorbed at the lower pressures. This is seen most clearly in the flattened capacity curve at 1600 psi until the temperature drops below $160^{\circ} \mathrm{C}$. Then, once the reaction begins to 
occur, the lower temperature produces slower kinetics. Again, this is most obvious if the slope of the blue curve is compared to that of the red curve at the beginning of the tet phase absorption.
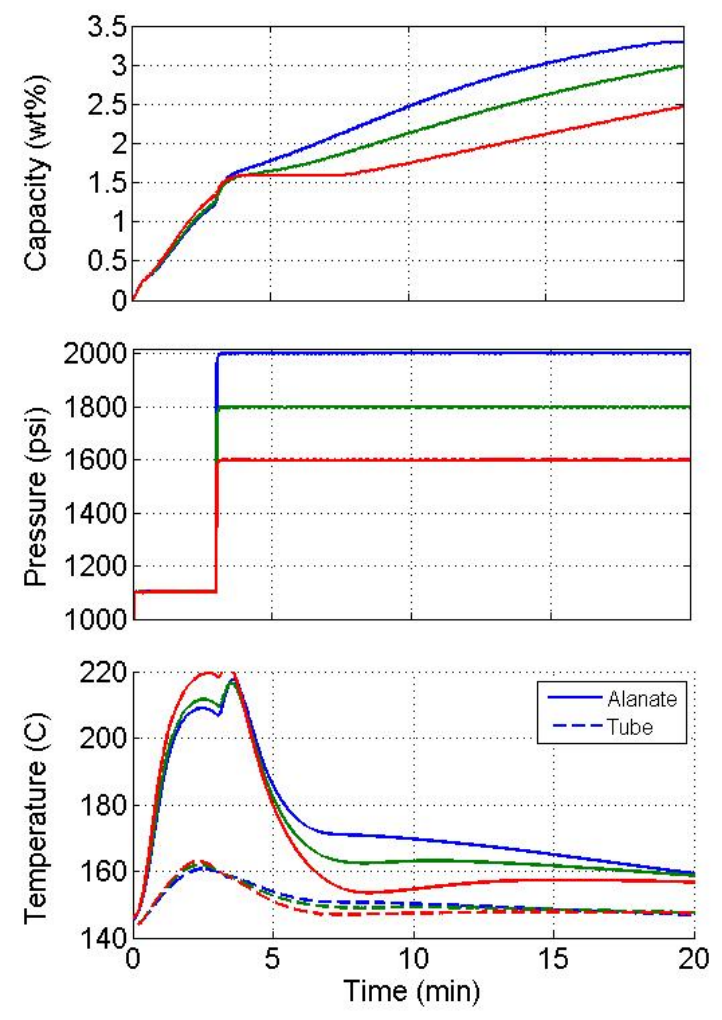

Figure 7. Experimental results showing the effect of hydrogen pressure on refueling rate.

The capacity shown in Figure 7 is the alanate capacity only, it is calculated from the mass of the modified storage media and does not include the mass of the tubes or the rest of the modules. But the system weight percent is what really matters and is what the model was used to optimize. If the system mass is included, then the capacity values from Figure 7 can be translated into system values. But first, the tube mass must be scaled with pressure. The Demonstration System was built for 2000 psi and has tubes with 0.120 ” thick walls. This thickness would be reduced for 1800 psi and 1600 psi. For our purposes here, a linear relationship can be assumed. So, tube thickness for 1800 psi would be 0.108 " and for 1600 psi would be 0.096 ”. If we neglect the heat exchanger shell and end plates and base the system mass on the tubes and alanate, then the relative system capacity can be easily calculated. We find that for a fifteen minute refueling time, the 2000 psi case produces a system capacity that is about $7 \%$ greater than $1800 \mathrm{psi}$ and about $23 \%$ greater than 1600 psi. Note that if the shell and end plates were included, the system capacity differences would be even more pronounced. These results validate the design of the Demonstration System for a hydrogen pressure of 2000 psi.

\subsubsection{Simulation Results}


To compare to the absorption test results just described, simulations were run with both the 1-D alanate tube model and the 2-D alanate tube model. Hydrogen pressure and oil temperature were used as boundary conditions in the models and transient simulations were run that calculated chemical composition, temperature, and hydrogen pressure throughout the tube. Recall that both models use the chemical kinetics rate expressions as well as the thermal properties that were developed from sodium alanate data. The difference between the models is that the 2-D model calculates axial variations in temperature, hydrogen pressure, and composition that are due to hydrogen transport in the porous solid material. We would expect that the inclusion of this additional physics would better predict the performance of the real system. Figure 8 displays the outcome of these simulations. The 1-D model predictions are shown on the left, the 2-D model predictions in the center, and the predictions of an enhanced 1-D model are shown on the right.

A comparison with Figure 7 indicates how closely the three sets of simulations predict the actual performance. As expected, the basic 1-D model does the worst job at matching the experimental data. The model over-predicts absorption rates resulting in higher capacities and temperatures. The hex phase absorption in the simulation is very fast. It is complete before the pressure step and results in a high peak temperature over $280^{\circ} \mathrm{C}$. The tet phase rates show the slowing effect with lower pressure, but are much higher than the experimental data. Like the hex phase, the simulated alanate temperatures are higher than the real system temperatures and the delay in the tet phase absorption for the 1600 psi case is not captured.

The 2-D model results show an improvement over the 1-D model. Absorption rates for both phases are lower, resulting in lower temperatures. The improvement is due to the hydrogen transport effect captured in the 2-D model. While the hydrogen pressure is used as a boundary condition, the calculated pressure throughout the tube is lower due to a model of the hydrogen permeation through the porous material and along gaps near the tube wall. The lower local hydrogen pressure results in lower reaction rates than are calculated in the 1-D model. However, the data in Figure 7 show even lower rates.
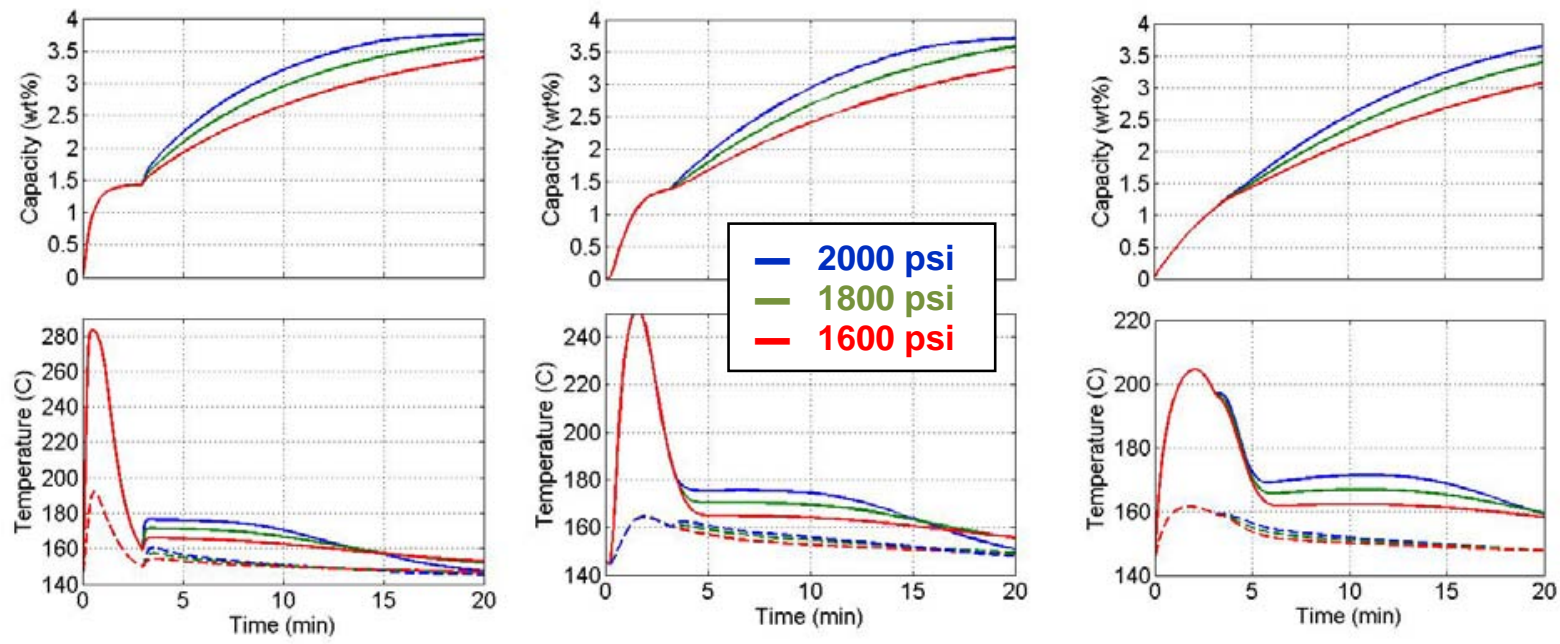

Figure 8. Simulation predictions of the effect of hydrogen pressure on refueling rate. 1-D model (left), 2-D model (center), and enhanced 1-D model (right). 
There are several explanations for the discrepancy between these models and the experiments. For one, the chemical kinetics model used in the simulations was developed using data from early cycles $(<10)$, but the data in Figure 7 was from cycles 48 - 50. Since we know that sodium alanate kinetics degrade with cycle [5], it is not surprising that the kinetics were over-predicted. We also know that the hydrogen pressure in a module tube varies along its axis and is much lower than the supply pressure [6]. The original 1-D model did not take this into account. For the 2-D model, the pressure gradient is calculated but the permeability model is not perfect. As discussed in [6], modifications to this model would be required to fully capture the hydrogen transport behavior of the Demonstration System.

The final simulation results, shown in the plot on the right in Figure 8, match most closely with the experimental data in Figure 7. The much slower hex phase absorption and the corresponding temperature response closely mimic the real system. The increase in temperature with the step up in pressure is captured, if not perfectly. The tet phase absorption rates and temperatures are also much closer. These results are from a modified version of the 1-D model. The chemical kinetics model was unchanged, but the alanate thermal conductivity was modified and a crude hydrogen transport model was added. The transport model was based on flow through porous media and was used to calculate an average hydrogen pressure in the tube. Transport model parameters and the correction to the alanate thermal conductivity were found by fitting results to Demonstration System data. In contrast, the parameters in the 2-D model were developed from various small sample experiments. So a critical difference between the models is that while the 1-D model could be tuned to fit experimental results well, the 2-D model did not require the system to be built to give good results, it provided a predictive capability.

\subsection{Effect of Coolant Flow Rate}

\subsubsection{Test Results}

Based on the results of the heat exchanger model that was described in Section 1.2.6., the Demonstration System was designed for a maximum coolant flow rate of $37.5 \mathrm{gpm}$. During the actual testing of the system, the coolant flow rate was limited to 30 gpm to limit the fluid pressure in the module shells. This flow rate was used for all of the refueling tests performed for GM.

To address the effect of coolant flow rate on refueling performance, tests were performed using the Demonstration System with $30 \mathrm{gpm}$ and10 gpm coolant flow rates. These refueling data are shown in Figure 9. As before, a pressure step procedure was used. However, for the lower coolant flow rate case, the initial pressure was reduced to limit the maximum alanate temperature to less than $230{ }^{\circ} \mathrm{C}$. Also, the pressure step was delayed in this case due to the slower cooling rate. However, as the plots indicate, while temperatures are noticeably different, the capacity is only slightly lower for the lower coolant flow rate. This is due primarily to the slower tet phase absorption rate. The reduced heat transfer rate is still high enough to allow this reaction to proceed at the maximum rate. The small delay in the transition from hex phase to tet phase absorption is insignificant compared to the total refueling time. So, for sodium alanate, the lower coolant flow rate would be sufficient. 

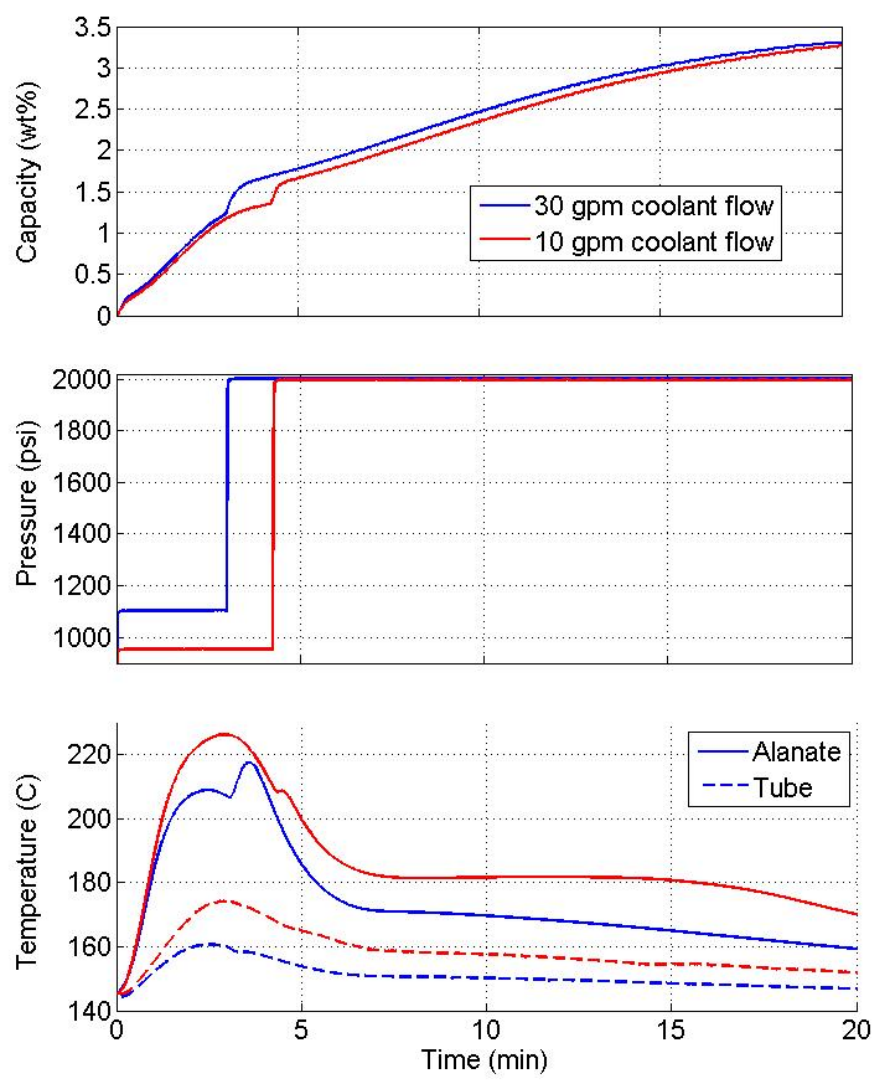

Figure 9. Effect of coolant flow rate on refueling rate

The implication of this result is that the module heat exchanger shells could have been designed for a lower oil pressure and been lighter. The shells for the Demonstration System modules were designed for an operating pressure of about 7 psig. In practice, the system was operated at a maximum pressure of about 6 psig corresponding to the 30 gpm flow rate. At 10 gpm, the maximum shell pressure was about 2.75 psig. Operating with the lower coolant flow rate reduced the pressure by more than a factor of two. For 7 psig operation, the module shells were made of 0.040 " thick high strength steel sheet metal that was reinforced with external ribs. Designing for a maximum pressure of 3 psig would have significantly reduced the structural requirement, resulting in a much lighter structure. However, because the Demonstration System was a first-of-a-kind prototype we erred on the side of conservatism and designed for the higher coolant flow rate.

\subsubsection{Simulation Results}

The 2-D model was used to compare to the experimental data in Figure 9. As before, the model was run using the hydrogen pressure and oil temperature from the experiments as boundary conditions. A heat transfer coefficient was used to model the difference in oil flow rate. For the $30 \mathrm{gpm}$ case, a value of $650 \mathrm{~W} / \mathrm{m}^{2} \mathrm{~K}$ was used and for the $10 \mathrm{gpm}$ oil flow rate, a value of 336 $\mathrm{W} / \mathrm{m}^{2} \mathrm{~K}$ was used. These values were based on the predictions of the heat exchanger model discussed in Section 1.2.6. Figure 10 shows the results from the model for both oil flow cases. 
As the middle plot shows, the applied hydrogen pressure was identical to the experiments. The predicted absorption rates and temperature response are somewhat different than the actual results, though. The model predicts a greater effect on hydrogen capacity due to the change in coolant flow rate. This is partly due to the much faster predicted kinetics. For the 30 gpm case, the result is a much faster rise and fall of the alanate temperature during the hex phase reaction. The tet phase reaction is then able to proceed earlier and at a greater rate. For the $10 \mathrm{gpm}$ case, the tet phase reaction appears limited by heat transfer and proceeds at a slower rate after the initial delay in the pressure step. Interestingly, this case matches quite well with the experimental data.
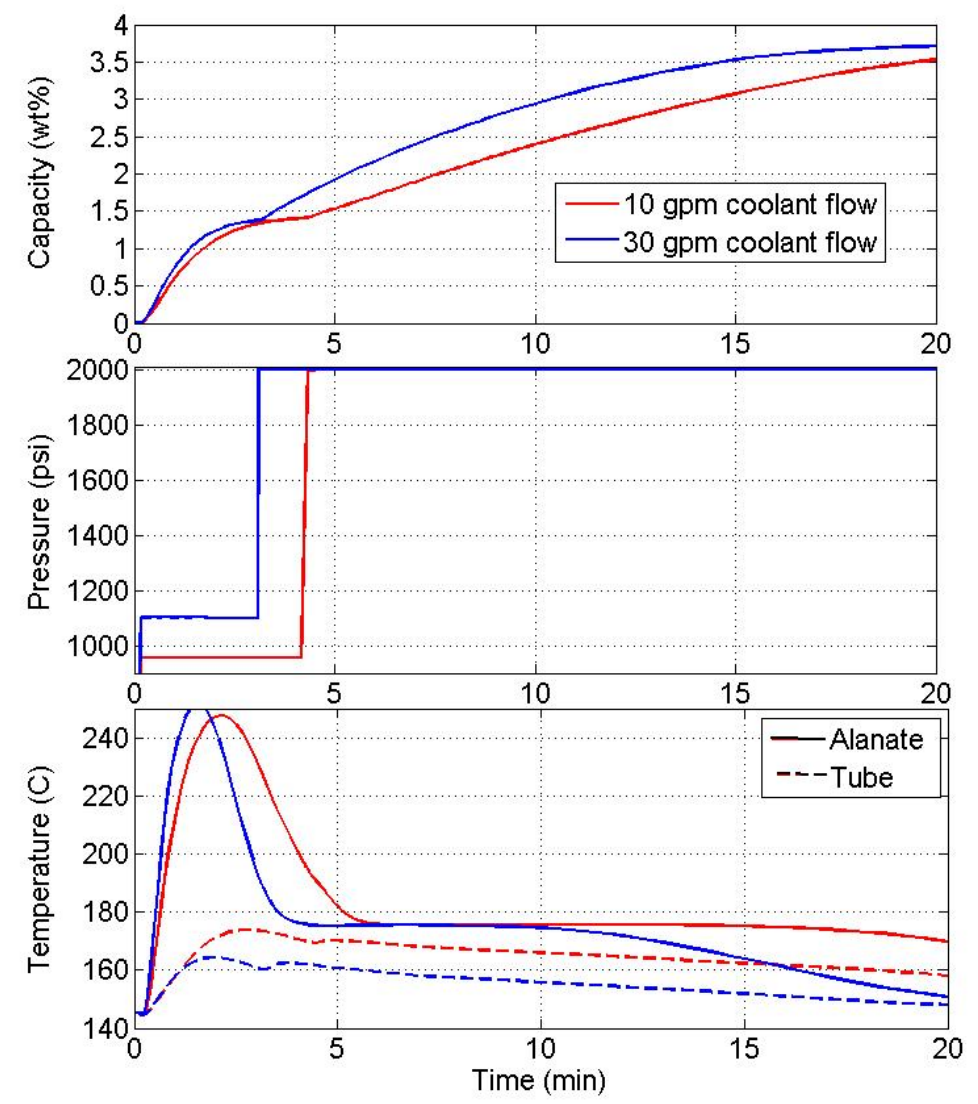

Figure 10. 2-D model predictions of the effect of coolant flow rate on refueling rate

Based on the simulation results shown in Figure 10, the higher coolant flow rate appears necessary to achieve rapid refueling. However, the data from Figure 9 shows little benefit in the higher coolant flow rate. In both model and experiment, the hex phase reaction is limited with hydrogen pressure to account for the reduced cooling. The result is that the hex phase reaction is largely unaffected by coolant flow rate in both model and experiment. The main difference is in the tet rate. The model predicts a rate that is high enough to be limited by heat transfer where the experimental rate was not. Just as with the pressure dependence, a better fit might have been possible if the model included a term in the kinetics expression to account for a rate reduction with cycle number. 


\section{SENSITIVITY STUDY - HYDROGEN DESORPTION}

For hydrogen delivery, the Demonstration System was designed to desorb hydrogen from one or more of the modules over a range of temperatures. A hydrogen flow controller was used to mimic a vehicle PEM fuel cell. This flow controller was used with manual flow rate control as well as with programmed, time-dependent hydrogen flow profiles. The modules were heated with the circulating fluid which was in turn heated by burning hydrogen from the modules. This was accomplished using a Sandia designed catalytic hydrogen burner [7]. The temperature and the flow rate of the fluid were controlled so that the system could supply the required hydrogen flow to the flow controller. Many different hydrogen delivery scenarios were tested with the system during the GM project. However, these tests were not conducted to map out the hydrogen delivery capabilities in a systematic way. That was the goal of this subtask.

\subsection{Effect of Temperature and Capacity - Tet Phase}

\subsubsection{Test Results}

Because the two alanate phases have quite different thermodynamics and associated dehydriding kinetics, we will consider them separately. The tet phase has a significantly higher plateau pressure than the hex phase, which contributes to the slower refueling rate. For desorption, however, this higher equilibrium pressure has the opposite effect. For a fixed temperature, the tet phase pressure provides a much higher driving force for hydrogen delivery which results in much higher rates. To provide a picture of the delivery potential for the tet phase, a single module was desorbed over three different temperature ranges. The resulting data gives hydrogen flow rate as a function of temperature and capacity as shown in Figure 11. Capacity is shown on the abscissa as a fraction of the tet phase. A value of one indicates that all of the sodium is in the form of $\mathrm{NaAlH}_{4}$. A value of zero indicates that all of the tetrahydride has been converted to $\mathrm{Na}_{3} \mathrm{AlH}_{6}$. Scatter in the data, especially in the high temperature case, is due to two sources. First, the data is a compilation of more than one test and second, the flow controller exhibited some noise.

To produce the data shown in Figure 11, a constant oil temperature was used. But, as desorption takes place, the alanate cools from the endothermic reaction. Cooling creates a radial temperature gradient with the lowest temperature at the centerline of the alanate tube. The higher the desorption rate, the larger the temperature gradient. So, the temperatures labeled on the plot are for reference and represent an average temperature for each case. For the high temperature case, the oil temperature was $182{ }^{\circ} \mathrm{C}$. It was $165^{\circ} \mathrm{C}$ for the medium temperature case and $140{ }^{\circ} \mathrm{C}$ for the low temperature case.

Hydrogen pressure during desorption is measured downstream of the module and is not necessarily representative of the pressure in the module. The pressure in the module must be higher to drive the flow of hydrogen. Higher hydrogen flow rate requires higher driving force. For consistency, the downstream pressure was kept nearly constant during these tests. By varying the flow controller, the pressure was kept between 3 and 5 bar which is reasonable for hydrogen delivery to a PEM fuel cell. 
As Figure 11 shows, hydrogen delivery rate is affected by both temperature and capacity. Higher temperature improves kinetics as well as raises equilibrium pressure resulting in higher desorption rates. Higher capacity means that more material is available to release hydrogen and so the rate is higher. In the same way, rate should go to zero as capacity goes to zero. Thus, the three sets of data approach one another at low capacity. A linear dependence on capacity is expected, but that is not what the data shows. The non-linear behavior shown in the figure is due to temperature variations and hydrogen transport within the module tubes.

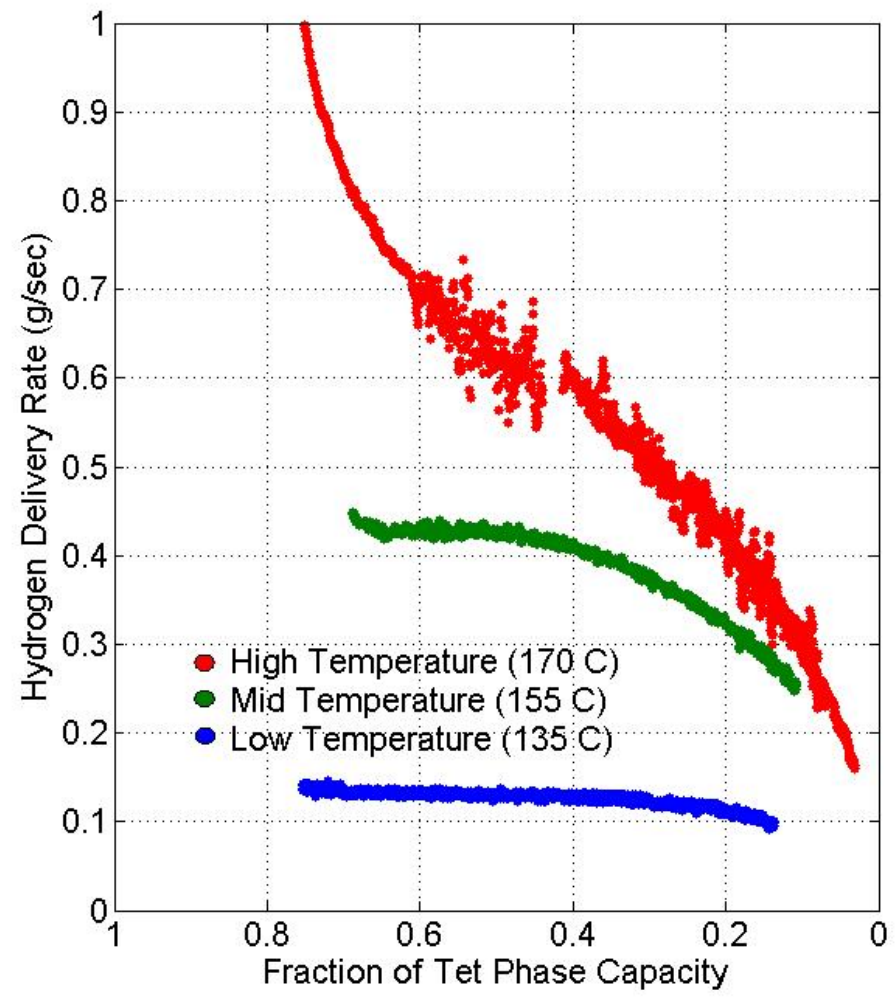

Figure 11. Effect of temperature and capacity on hydrogen delivery rate of the tetrahydride phase of a single module

The curves in Figure 11 show that a broad range of hydrogen delivery rates can be achieved by varying temperature between $135^{\circ} \mathrm{C}$ and $170{ }^{\circ} \mathrm{C}$ for the tet phase. Rates higher than 1 gram per second can be produced by a single module at high temperature and capacity. Conversely, at the low temperature it is difficult to achieve $0.15 \mathrm{~g} / \mathrm{sec}$. Note that over the first quarter of the tet phase capacity, the desorption rate of the material is difficult to separate from the gaseous hydrogen leaving the module, so this data has been omitted.

Overall, the tet phase hydrogen delivery rates are sufficient to meet realistic vehicle requirements. The DOE targets for on-board hydrogen storage systems include a minimum full delivery rate of $0.02 \mathrm{~g} / \mathrm{sec} / \mathrm{kW}$. So, for a $100 \mathrm{~kW}$ fuel cell system, the hydrogen storage system would have to deliver $2.0 \mathrm{~g} / \mathrm{sec}$. One of the Demonstration System modules has a capacity of 750 grams of hydrogen. Ten of these modules would be needed to provide a reasonable range for a $100 \mathrm{~kW}$ fuel cell. So, a per module flow rate of $0.2 \mathrm{~g} / \mathrm{sec}$ would be needed to meet this 
requirement. From Figure 11, this could be accomplished over the full capacity of the tet phase material at temperatures above about $155^{\circ} \mathrm{C}$.

\subsubsection{Simulation Results}

As with the absorption tests, both the 1-D and the 2-D models were used to simulate the hydrogen delivery performance of the Demonstration System. These simulations were performed for the high temperature and low temperature cases from Figure 11. The models were run using the oil temperature and downstream hydrogen pressure as boundary conditions. Transient hydrogen desorption rates, temperatures, and, except for the 1-D model, pressures were calculated. The rate and pressure results from these simulations are shown in Figure 12.
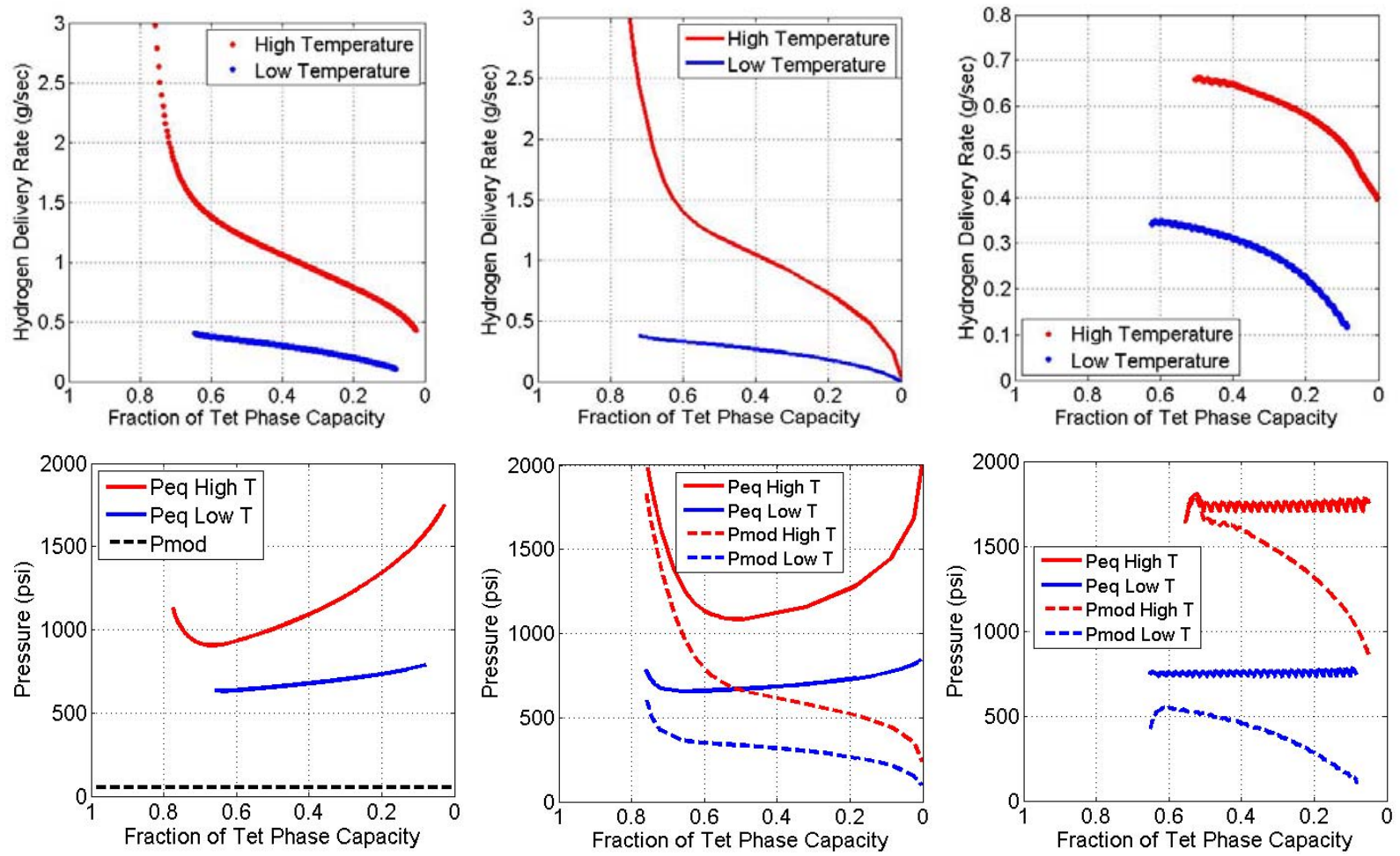

Figure 12. Simulation predictions of the effect of temperature and capacity on hydrogen delivery rate of the tetrahydride phase of a single module. 1-D model (left), 2-D model (center), and enhanced 1-D model (right).

Compared to the data from Figure 11, the 1-D model over-predicts the delivery rates at both temperatures. The rates at the high temperature are about twice what was measured, although the temperature and capacity effects seem to be captured in the shape of the curve. The low temperature rates are also on the order of twice as high and show more of a slope with capacity than the measurements. The difference between measured tet phase desorption rates and the 1-D model predictions can be primarily attributed to hydrogen transport. The plot of pressures from the 1-D model shows that the equilibrium pressures are very large compared to the applied module pressure of 50 psi (3.5 bar). In the experiments, the local pressure within the module tubes is not measured, but must be significantly higher than the 3 to 5 bar downstream pressure. 
This effect is included in the 2-D model which calculates a local pressure at each radial and axial position based on the permeability model. This is evident in the plot of pressures from the 2-D model shown in the lower center of Figure 12. Volume averaged pressures from the 2-D model results are shown. While equilibrium pressures are similar to the 1-D model, the calculated module pressures are quite different than the constant value used in the 1-D model. Interestingly though, these elevated local pressures do not significantly affect rates which are quite similar to the 1-D results. It seems that although the 2-D model predicts elevated local pressures, the tet phase equilibrium pressure is high enough that this has little effect.

An even higher local pressure is predicted by the simple transport model in the modified 1-D model. The result, shown in Figure 12 on the right, is a better match to the high temperature rate data. Here the calculated module pressure is close enough to the equilibrium pressure to have a noticeable effect on hydrogen desorption rate. For the low temperature case, however, this model also over-predicts the rate. The implication from these results is that neither transport model captures the exact behavior of the real system.

\subsection{Effect of Temperature and Capacity - Hex Phase}

\subsubsection{Test Results}

The hexahydride phase of the alanates absorbs hydrogen rapidly, but desorbs slowly at reasonable temperatures. As mentioned previously, this is due to the material thermodynamics. The low plateau pressure of the hex phase requires high temperature to provide a large enough driving pressure for hydrogen delivery to a fuel cell. During the Demonstration System testing, we limited the operating temperature of the system to $220^{\circ} \mathrm{C}$. Elastomeric seals and the flammability of the heat transfer fluid were two considerations for this limit. While the hex phase material could produce usable hydrogen flow rates at this temperature, they were significantly lower than the tet phase rates at lower temperature.

As with the tet phase data, new results were needed to map delivery rate with temperature and capacity. Because of the upper temperature limit and the relatively low rates, only two temperature regimes were explored. Figure 13 shows the results. The abscissa is now a fraction of the hex phase. As with the data in Figure 11, this data is a compilation of various desorption tests. The resulting scatter in the data is most noticeable at the high temperature.

The fluid temperatures used for these sets of data was $217^{\circ} \mathrm{C}$ for the high temperature case and $190{ }^{\circ} \mathrm{C}$ for the low temperature case. As with the tet phase data, the temperatures listed in the plot represent an average temperature of the alanate. Also like the tet phase data, the downstream hydrogen pressure was controlled to between 3 and 5 bar using the hydrogen flow rate. 


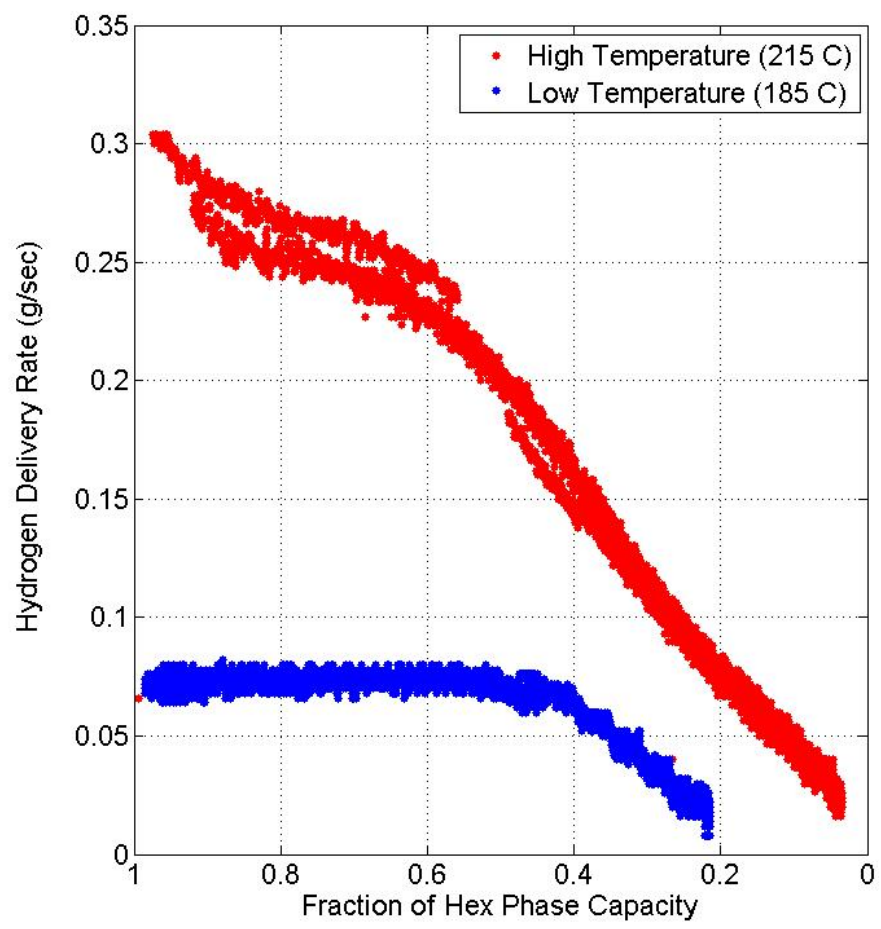

Figure 13. Effect of temperature and capacity on hydrogen delivery rate of the hexahydride phase of a single module

Hex phase rates also show a significant dependence on both capacity and temperature although a more limited range of rates is achievable. At the high temperature, rate drops with capacity over the entire range. However, at the low temperature, rate is steady until the hex fraction drops to about 0.5 . At that point the rate then drops steadily. A similar trend was seen in the tet phase results.

Overall, the rates in Figure 13 are significantly lower than the tet phase rates. Even at the upper temperature limit and full capacity, the maximum rate is less than $0.3 \mathrm{~g} / \mathrm{sec}$. Recalling the DOE target discussed earlier, a ten module system would not be able to meet the delivery target beyond about half of the hex phase capacity where the high temperature rate drops below 0.2 $\mathrm{g} / \mathrm{sec}$. However, as is described in [6], the Demonstration System modules have hydrogen transport limitations which could be overcome with a design improvement that might allow for improved delivery rates.

\subsubsection{Simulation Results}

1-D and 2-D model results for hex phase hydrogen delivery are shown in Figure 14. As with the tet phase results, the oil temperature from the high and low temperature tests were used as model inputs along with a pressure boundary condition. Due to the lack of a transport model, the 1-D model predicts much higher rates than were actually achieved. In this case the rates are about a factor of three higher than the data. 
In contrast, the 2-D model predicts rates for the hex phase that are lower than measured experimentally at high and low temperatures. Unlike for the tet phase, the porous media permeability results in a small difference between local hydrogen pressure and equilibrium pressure of the material as shown in the lower center plot of Figure 14.

A similar effect shuts off the reaction in the modified 1-D model before the full hex capacity is desorbed. This model under-predicts the high temperature rates and over-predicts the low temperature rates over most of the capacity.
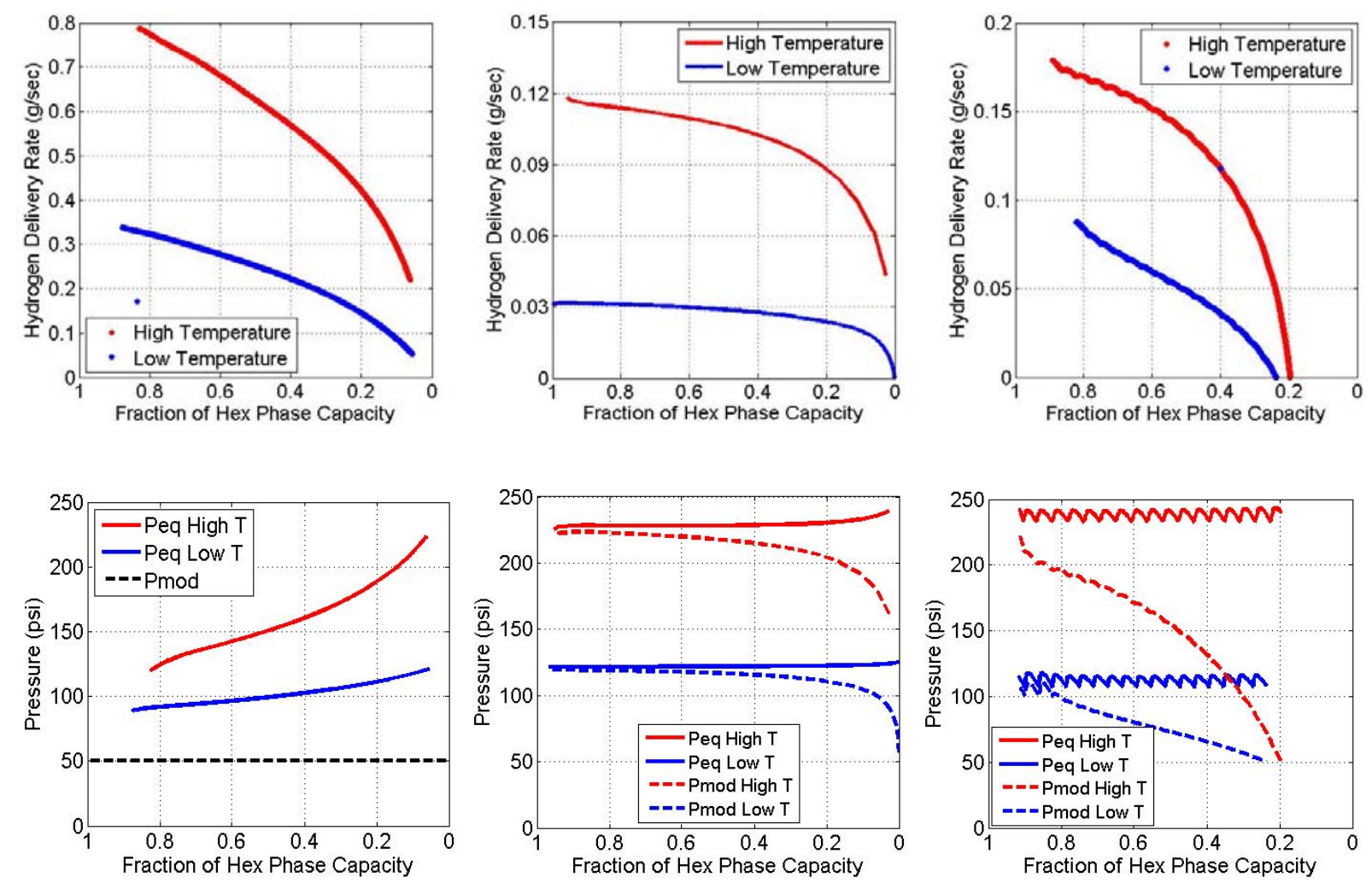

Figure 14. Simulation predictions of the effect of temperature and capacity on hydrogen delivery rate of the hexahydride phase of a single module. 1-D model (left), 2-D model (center), and enhanced 1-D model (right). 


\section{SUMMARY AND CONCLUSIONS}

A study of the key parameters affecting hydrogen refueling and delivery rates of the GM/SandiaHydrogen Storage Demonstration System has been carried out. For refueling, the effects of hydrogen pressure and coolant flow rate were investigated. For delivery, the effects of temperature and capacity were investigated. Experimental data from both of these investigations were compared to computational simulations from a 1-D and a 2-D model of the Demonstration System.

Refueling data from the Demonstration System shows that the tetrahydride phase of sodium alanate is by far the rate limiting step. The hexahydride phase hydrides much faster and accounts for only a small fraction of the total refueling time. Simulations during the design phase of the Demonstration System predicted that system mass efficiency would be optimized if the tet phase was hydrided with a hydrogen pressure of 2000 psi. These simulations were performed using a 1-D radial model with coupled chemical kinetics and heat transfer.

Experiments performed with hydrogen pressures of 1600 psi, 1800 psi, and 2000 psi validated the model predictions. At $2000 \mathrm{psi}$, system mass efficiency was conservatively estimated to be $7 \%$ better than the 1800 psi case and 23\% better than the 1600 psi case. Because the system was designed for a maximum pressure of 2000 psi, a higher pressure case could not be performed. However, the decrease in relative change as pressure was increased suggests a maximum near 2000 psi.

While the 1-D model captures the relative trends of the Demonstration System performance, direct comparison with data shows less than desired quantitative agreement. The most significant reason for this disagreement is the lack of a mass transfer model in the 1-D simulation. The sintered solid sodium alanate, though porous, provides a resistance to hydrogen flow. Using data from small, flow-through experiments, a permeability model was developed and included in a 2-D axisymmetric representation of the Demonstration System geometry. Thus, mass transfer was added to the heat transfer and sorption kinetics solved simultaneously in the 1-D model.

By comparison, the 2-D model simulation more closely matched the actual data. However, simulated absorption rates were still higher than measured. Some of the difference can be attributed to a kinetic degradation of sodium alanate with cycling, but probably not the full difference. A modification to the 1-D model that included a hydrogen transport equation with parameters fit to module data was able to improve on the 2-D model results. However, this model was more empirical than physically based making it much less useful as a design tool.

The predictive capabilities of the models were also tested with respect to coolant flow. Using a combination of the 1-D hydride model and a heat exchanger model, the Demonstration System had been designed for a coolant flow rate of $37.5 \mathrm{gpm}$. This was a conservative design point, though, and a lower flow rate of $30 \mathrm{gpm}$ was used for all of the GM refueling tests. To determine the effect of even lower coolant flow, a refueling test was conducted with oil flowing at $10 \mathrm{gpm}$. This scenario was also simulated with the 2-D model. Though not in perfect 
quantitative agreement, both model and experiment indicated that the lower coolant flow rate could be used to refuel nearly as fast as the higher flow rate.

This result can be attributed to the relatively slow tet phase hydriding rate. The cooling system had been conservatively designed to handle the hex phase rates. However, if the hex phase is slowed with a reduced hydrogen pressure then the slower cooling rate can still limit peak temperatures and cool the system to and maintain the optimum temperature for tet phase absorption. With this lower oil flow rate, the Demonstration System heat exchanger shells could have been lightened, improving the system mass efficiency. This was not important for the prototype system since for experimental flexibility its mass was not optimized, but would be an important consideration for a production unit.

In addition to refueling, a hydrogen delivery parameter study was carried out. Both tet and hex phase delivery rates were mapped as a function of temperature and capacity. The experimental results for the tet phase revealed that even with the hydrogen transport limitation of the long module tubes, DOE targets for hydrogen delivery could be met with moderate temperatures over the full capacity. In contrast, hex phase rates were too low due to the lower equilibrium pressure. To use the full storage capacity of sodium alanate, the Demonstration System would require transport enhancement to achieve rates closer to the 1-D model predictions.

A comparison of the different model results with hydrogen delivery data indicated that capturing the effect of hydrogen transport in the porous media was difficult. Both the 2-D model and the modified 1-D model calculated local pressures that varied with temperature and flow rate, but neither model was able to closely match the data. The 2-D model over-predicted tet phase rates and under-predicted hex phase rates. The modified 1-D model was only slightly better despite having been fit to experimental data. 


\section{REFERENCES}

1. D. E. Dedrick et al., Heat and mass transport in metal hydride based hydrogen storage systems, Proceedings of the 2009 ASME Summer Heat Transfer Conference, July 19-23, 2009, San Francisco, California USA

2. T. A. Johnson, S. W. Jorgensen, and D. E. Dedrick, A Vehicle-Scale Sodium Alanate Hydrogen Storage Demonstration System, (in preparation for publication)

3. D. E. Dedrick et al., Thermal properties characterization of sodium alanates, Journal of Alloys and Compounds, Vol. 389, pp. 299-305, 2005

4. A. Rodriguez-Sanchez et al., Expanded graphite as heat transfer matrix in metal hydride beds, International Journal of Hydrogen Energy, Vol. 28, pp. 515-527, 2003

5. T. A. Johnson and D. E. Dedrick, Durability Study of a Vehicle-scale Hydrogen Storage System, SAND2010-XXXX, Sandia National Laboratories, Livermore, CA, (in preparation for publication)

6. T. Voskuilen, D. E. Dedrick and M. P. Kanouff, System-Level Permeability Modeling of Porous Hydrogen Storage Materials, SAND2010-0254, Sandia National Laboratories, Livermore, CA, January, 2010

7. T. A. Johnson and M. P. Kanouff, Performance Characterization of a Hydrogen Catalytic Heater, SAND2010-2474, Sandia National Laboratories, Livermore, CA, April, 2010 


\section{DISTRIBUTION}

4 Scott Jorgenson

Chemical and Environmental Sciences

General Motors R\&D, Planning and Fuel Cell Activities

Mail Code: 480-106-269

30500 Mound Road

Warren, MI. 48090-9055

4 Monterey Gardiner (DOE/EERE)

Forrestal Building

U.S. Department of Energy

1000 Independence Ave., S.W.

Washington, DC 20585

$1 \quad$ MS0824 Joel Lash

1 MS0836 Terry Aselage

1 MS9001 Chris Moen

1 MS9153 Mike Hardwick

1 MS9035 Paul Spence

1 MS9054 Bob Carling

1 MS9054 Art Pontau

1 MS9052 Jay Keller

1 MS9409 Daniel Dedrick

1 MS9409 Neal Fornaciari

2 MS9018 Central Technical Files 8944

2 MS0899 Technical Library 4536
1510/1512 (electronic) 1514 (electronic) 8005 (electronic) 8220 (electronic) 8224 (electronic) 8300 (electronic) 8360 (electronic) 8367 (electronic) 8365 (electronic) 8365 (electronic) 



\section{Sandia National Laboratories}

